\title{
Preserving Our Digital Heritage: Experiences from the Pelikonepeijoonit Project
}

\author{
Mikko Heinonen $^{1}$ and Markku Reunanen ${ }^{2}$ \\ ${ }^{1}$ University of Tampere \\ mikko.heinonenaiki.fi \\ ${ }^{2}$ University of Art and Design Helsinki \\ markku.reunanen@iki.fi
}

\begin{abstract}
Pelikonepeijoonit is a private Finnish computer and games console museum. Similar to most hobbyist collections, the first items were acquired out of personal reasons. During its eight years, the collection has grown significantly and started to shift towards a digital heritage preservation project. In this paper, we present the history of Pelikonepeijoonit, coupled with observations made throughout the years. A supporting study was also conducted among the Finnish game/computer collector community to gain additional points of view and validate the personal observations. The results of this study are presented in relation to digital heritage to link the two practices, the collector circles and the cultural heritage. Finally, we present some suggestions for further work based on the current and future challenges of the field.
\end{abstract}

Keywords: Digital heritage, computer hobbyists, museum.

\section{Introduction}

Pelikonepeijoonit ("Game Machine Rascals") is a private Finnish computer and games console museum project run by three collectors. During its eight years, the project has evolved from a small personal collection to a digital heritage preservation project, also bringing together other individuals with shared interests. The Pelikonepeijoonit museum currently hosts around 250 different devices, thousands of games and several hundred related items. The collection can be viewed online at http://www.pelikonepeijoonit.net/

In this paper, we shall discuss the overall goals of the Pelikonepeijoonit project, its current status, and draw conclusions on the meaning and challenges of such work. Connections to home computer and game console history as well as digital heritage are made in order to rise above the grassroots level of a personally motivated hobby. The apparent gap between official digital heritage initiatives and hobbyists is not easily bridged, so we shall also propose some approaches on how the two communities could better be brought together for the benefit of both.

\subsection{Time Span of the Collection}

The museum-owned devices mostly range from the 1970's to the 1990's, which obviously coincides with the domestication of the microprocessor and related appliances. 
Suominen [19] and Saarikoski [14, 15] provide an overview of the period from a Finnish point of view. The work of Suominen mainly deals with the early mechanisms of technology domestication in Finland, whereas Saarikoski focuses especially on hobbyist use such as computer games. The compact overview by Haddon [7] provides an international perspective to the same period. For more in-depth discussion, we direct the reader to Kent [9], Forster [4] and Bagnall [1]. From these sources alone, the vast number of different collectibles becomes apparent, setting a challenging goal for museums wishing to obtain a comprehensive collection. As an example, according to Bagnall [1], over 1200 games were released for the Commodore 64 in both 1987 and 1988.

\subsection{Digital Heritage Preservation}

We can view digital heritage as a specific part of our cultural heritage. So far, the major focus has been on archeological artifacts, and while modern technology is widely used in these projects (often called digital cultural heritage), the technology itself has not been viewed as something in urgent need of preservation. When compared to tangible artifacts, the digital artifacts have two notable properties: we can reproduce them infinitely, and they are easily lost for good. The thirty-year old home computer history is already in threat of becoming lost heritage because of aging hardware and software, inaccessible media, lack of expertise and supportive legislation [20].

Books and other written material are one way of preserving the heritage, but even more important is the preservation of artifacts in order to facilitate future research. As of late, this need has started to gain official recognition, which has lead to initiatives such as the UNESCO charter [20] and the EU-funded DigiCULT [3]. In Finland, Suomen Peliautomaattihistoriallinen Seura is a society of coin-operated arcade machine collectors [18]. Personal collections and community websites such as old-computers.com with archives are two common ground-level approaches to the preservation. From the point of view of a wider audience, such approaches are static and communicative by nature, in contrast to so-called emulators running old software, which provide users with an interactive experience. From the heritage and accessibility perspectives, it is unfortunate that emulation is inherently illegal because of copyright legislation.

\section{History of Pelikonepeijoonit}

The Pelikonepeijoonit project stems from the individual collections of three Finnish hobbyists. Mikko and Ville Heinonen had started collecting different home computers and items related to gaming in the early 1990s, and were joined by Manu Pärssinen around 1998. After a period of searching for information on their items on the Internet, they noticed that in fact, they should start a website based on their collection to assist other like-minded hobbyists. The first version of the site was launched on 2 May of 1999 at the somewhat non-intuitive address http://gamma.nic.fi/ mikkohoo/peijoonit. The group did some small-scale dissemination of the site in Internet newsgroups and among friends. However, as the interests were purely non-commercial, they did not carry out any large-scale marketing effort. The site consisted of simple HTML pages for each computer or video game system in the Pelikonepeijoonit collection, presenting 
an image of the item and a basic technical description. Manu Pärssinen completely made the web design, while Mikko Heinonen supplied the core of the written material. From the beginning, the site was aimed at an international audience and was therefore written in English.

Judging by the response the site received, the initial estimate of the group was correct. The site received a number of mentions on other websites, in industry magazines and newspapers $[18,21]$ and the Pelikonepeijoonit group were interviewed for several different media. Manu Pärssinen received numerous web awards for his design work on the site. The collection also increased rapidly during the months following the launch of the site, mainly through trades from other parts of the world, trips to different countries, and through donations. Looking at the list of updates from 1999 [10], we see that updates on the website took place nearly every day, with new items being added weekly. The same pace continued well into the year 2000 [11] and beyond. During this time, the collection expanded from containing around 70 computers and video game systems to around 160.

\subsection{Site Visitors}

It is hard to estimate the actual number of people visiting the site, since reliable visitor counters were unavailable in 1999. By the time the site turned 2 years old in 2001, it had accumulated 28000 visitors. The IPstat counter on the main page, started $21 \mathrm{Au}-$ gust of 2000, lists 157199 real views and 70592 reloads up to 10 April of 2007 [8]. As site updates have been significantly slower in the past year due to time issues with the maintainers, the bulk of these visitors were accumulated before 2006 .

In addition to containing information on the items owned by the group, the Pelikonepeijoonit website has hosted pages related to general information for computer and video game collectors. The first one of these, the PAL-NTSC compatibility page, was added in August of 1999. E-cards and similar entertainment items were included from the beginning. Visitors to the site were active in submitting additions and changes to the information pages, increasing their usefulness and popularity.

\subsection{Co-operation with Businesses and Hobbyists}

As the site grew in popularity, the Pelikonepeijoonit group received requests for cooperation from different fields of the gaming business. In 2000, Mikko Heinonen became a game reviewer at the website Sooda.com, later on at Peliplaneetta.net, partly due to merits and expertise from the Pelikonepeijoonit project. Manu Pärssinen has gained reputation as a game news journalist and reviewer on a number of websites. These positions were both partly due to the reputation received while working on Pelikonepeijoonit, and very helpful in terms of adding items to the collection. Press copies of games and promotional material were added to the archive after review.

In 2002, Pelikonepeijoonit were present at the GameWorld trade fair with their own exhibition [12], sponsored by Sanoma Magazines. This tradition has continued with smaller stands in 2003 (GameWorld), 2005 (Assembly) and 2006 (DigiExpo). In early 2003, the Tyrvää museum in Vammala, Finland, held an exhibition on "Digital Archeology" based on selected items from the Pelikonepeijoonit collection [13]. 
One of the key goals of the Pelikonepeijoonit project has been to bring hobbyists together both online and offline. The group arranged their first collector meeting, $P e$ likonepeijaiset, in July 2001. With the exception of 2002, similar events occurred each summer. The amount of visitors to these events has been between 20 and 30 people. The meetings have featured thematic exhibitions such as the collection of Sega items in 2006, shown in Figure 1. In February 2007, the first "Pelikonepeijaiset Winter" had taken place with around 10 attendants. The website also features a message board, which has some 20 active users (over 2000 registered), 1700 topics, and 9000 posts.

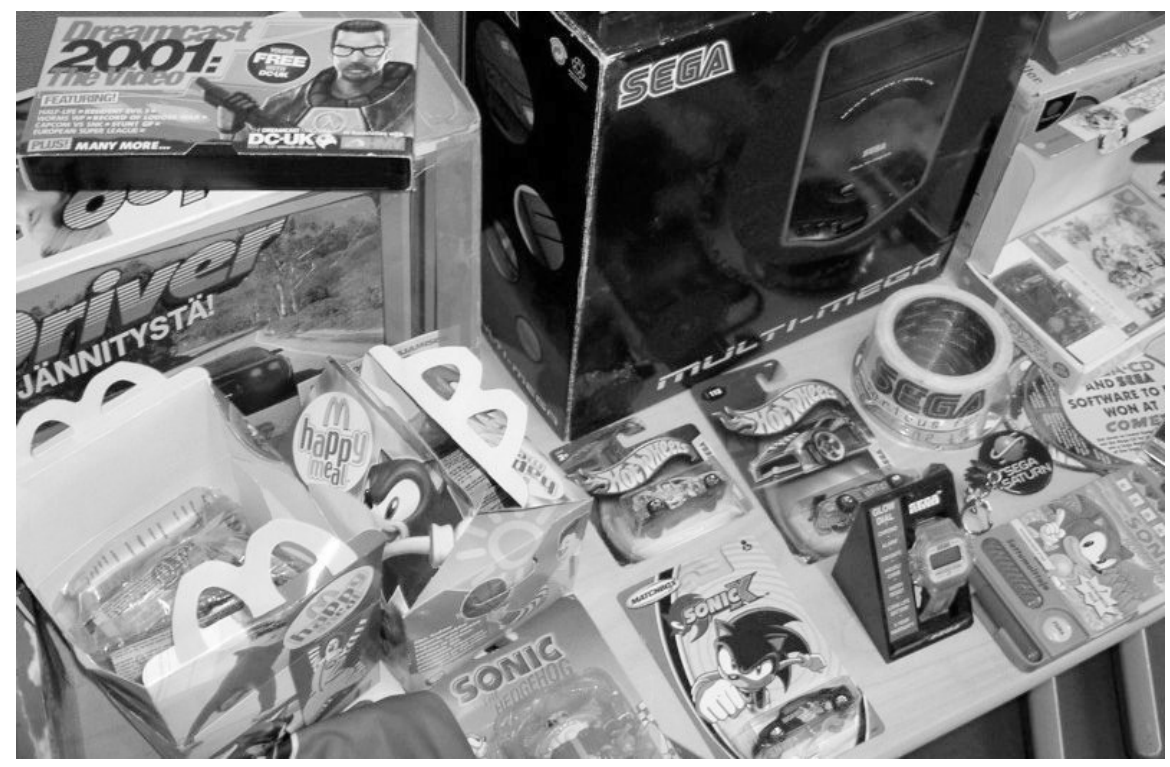

Fig. 1. Sega collectibles (image provided by Manu Pärssinen)

\subsection{Future}

Currently, the Pelikonepeijoonit group is extending collaboration with their visitors by rebuilding the site in Wiki format. The site will still include the information on the computers and videogames, but much more will be available for site visitors to edit. The idea is to manage better the wealth of material accumulated on the website, and to enable visitors who 'know better' to complement the information more easily than has previously been possible. The group hopes to encourage visitors to participate more in the development of the website, keeping the information more up-to-date, as well as simplifying updates for the site maintainers.

With the large number of artifacts, it is not feasible for individual collectors to maintain exhaustive collections of digital heritage items. During the course of the Pelikonepeijoonit project, the group has had to limit their collection on several fronts-such as leaving out most PC standard hardware, Game \& Watch type digital games, systems with only a single built-in game, and so on. While most of the 'unwanted' items have so 
far found new homes with other collectors of differing interests, having to limit collections due to space restraints necessarily leads to material being discarded.

As years have passed and the Pelikonepeijoonit collection has grown, more emphasis has been laid on improving the general awareness on digital heritage issues-this article, indeed, forms part of these efforts. In the future, the Pelikonepeijoonit group hopes to work further to promote the preservation of home computing and digital gaming artifacts.

\section{Supporting Study}

A small-scale supporting study, based on a questionnaire, was conducted to understand better the hobbyist culture and to validate the experiences gained in the Pelikonepeijoonit project. While limited in scope, the results gained still reveal relevant trends and provide for a better generalization of the personal observations. The study addressed active Finnish computer, console, and game collectors and was implemented as a structured questionnaire.

\subsection{Questionnaire}

There were sixteen, mostly qualitative, questions altogether in the questionnaire. The number of questions was few to avoid frustrating the respondents. The themes addressed were roughly as follows:

- Demographic issues such as age, sex and occupation

o Personal motivation

- Methods of obtaining collectibles

- Problems and challenges of the hobby

o Methods of information retrieval

o Personal views on the hobby

The questionnaire was distributed electronically and advertised in various relevant forums such as IRC channels and the Pelikonepeijoonit discussion board, which reaches a large portion of the Finnish collectors. The answers were collected via email and analyzed thereafter. The respondents were asked not to reply onto the board itself, so that the previous answers would not skew the results. Before the launch, a pilot test was run to ensure the questions were understandable and to the point.

\subsection{Results}

We received fifteen responses in all, considered a representative sample of the Finnish collectors since the hobbyist circles are small. Such a sample does not allow for realistic quantitative analysis, so the material obtained was used to build a profile of a typical Finnish collector, to understand different points of view, and to discover trends.

According to our study, a typical Finnish collector is a male in his late twenties or early thirties, working in an information technology related field. The personal motivation for collecting often relates to machines owned in childhood, for example, Commodore computers or Sega consoles. We can explain this nostalgia by the fact 
that the persons have been in their late childhood or early teens in the eighties, which coincides with the home computer and microprocessor revolution-one could say that they represent the first generation that grew up with electronic toys and computers. Game playing has always been a popular use for the machines [15] and every single informant reported it as an important use for their collection.

Flea markets, Internet auction sites such as eBay, recycling centers and social networks are the most popular sources for collectibles. Out of these four, especially the social networks are held in high regard. The biggest problem in the acquisition process is the high price of items, partly due to postal fees and partly due to increasing prices in auctions. The acquisitions have been funded by savings from a daily job and, to a lesser extent, by the trading of duplicate items, or even a study grant. A representative collection of items requires considerable space for storage, a problem reported by half of the collectors. Another typical problem was the breakage of old hardware, coupled with the difficulty of obtaining spare parts.

The wide use of the internet as a communication channel and source of information is hardly a surprise, considering the technical nature of the hobby. Every single informant had used the Internet in some form for these purposes. The most popular sources of information mentioned were hobbyist web sites, search engines (usually Google) and discussion forums. Usenet news and modem-based bulletin board systems (BBS) had been of importance previously, but gradually lost their significance. The use of e-mail was almost completely omitted in the answers, which notably conflicts with the aforementioned importance of social networks. Most likely, this conflict has more to do with e-mail not being regarded as "Internet use" instead of hobbyists not using it.

\section{Digital Heritage and Hobbyists}

While museum authorities and official bodies are slowly starting to catch up with the need for digital heritage preservation, significant efforts have taken place among the individual hobbyists for quite some time already. Bridging the gap between the personal aspirations of individual collectors and the needs for a large-scale history preservation project will pose a challenge for any organization aiming to approach digital heritage preservation on a larger, better-coordinated scale. In addition to this, the scene is continuously changing, requiring any parties operating in the field to be able to assess future implications.

\subsection{The Value of Personal Collections}

As we stand, the responsibility for the systematic preservation of digital culture rests strongly on the shoulders of individual hobbyists. While public organizations are now starting to show limited interest towards the hobby, many collectors have already worked on their personal collections for well over ten years, preserving remarkable amounts of material that would otherwise most likely have been destroyed. Their motives for collecting are largely personal, with less focus on abstract goals such as digital heritage preservation. Regardless of the aims, collectors possess skills essential for the preservation efforts: they are networked (these days, mainly through the internet), they know the distribution channels, and they are used to dealing with aging hardware. 


\subsection{Current Trends}

Looking at current developments within the media, we can see that the popularity of 'retro' is increasing. As a sign of this, the popular game player and game industry magazine Edge has published several special issues on the topic: Edge presents Retro [5] and three issues called Edge presents File [6]. These publications concentrate on historical computers and games machines, their collectability, and old product reviews from the beginning of the 1990s, when they started Edge. Combined with similar, albeit shorter accounts in other media, we can see that the topic is starting to gain increasing mainstream press interest as well. Well-known game characters such as Mario have already turned into pop culture icons, used by contemporary artists. The "I am 8-bit" exhibition in 2005 featured works from over 100 authors [16].

The Game On exhibition has been touring different museums of the world during the past few years, visiting Finland in 2003. The exhibition consists of display exhibits of the most popular arcade games, home computers and video game systems, as well as over 100 playable games for the visitor audience to try, ranging from the world's first computer game, Space War, to the latest offerings on the PlayStation 3 and Nintendo Wii consoles [17].

As current computers, game consoles and even handheld devices, such as mobile phones, are hundreds of times more powerful than vintage computer and gaming hardware, software emulation is becoming more and more feasible. While it started out as single projects to emulate popular hardware like the Commodore 64, emulation is now widespread and they attempt to emulate nearly every system in existence. Indeed, in the Game On exhibition the oldest games featured actually ran emulated on modern hardware.

New games machines, such as the Nintendo Wii, the Sony PlayStation 3 and the Microsoft Xbox 360, both emulate their predecessor hardware to be able to provide backwards compatibility and offer users downloads of older software for purchase. The Nintendo Wii Virtual Console is entirely based around the concept of emulating older Nintendo, Sega, and NEC game consoles. The user may purchase digitally distributed copies of these games to play on their system through an emulation layer.

While game manufacturers have embraced emulation for their purposes, hobbyist projects are generally not approved of. The owners of copyrights have systematically shut down websites containing ROM images (i.e. digital copies of the early game cartridges). Hobbyist groups have worked together with owners of copyrights to bring, say, hundreds of Commodore 64 and Amiga titles legally available for download on the Internet, but there are still countless systems which are inherently illegal to emulate.

\subsection{Future Directions}

As the popularity of 'retro' is on the increase, vintage games, machines and computers, and their software are continuously increasing in value. We can see this on auction sites such as eBay, and it was clearly brought up in the results of our study. At the same time, however, emulation is becoming more effective and allowing more and more people to access past software without the need to purchase or preserve special hardware. It is difficult to say how this will affect pricing in the end-emulator users may settle for seeing the product running on their system, or may want to acquire the actual hardware to be able to experience it better. 
While the preservation of software in ROM dump files and disk images for emulation purposes has contributed vastly to preserving the software and program code of these titles, the original boxes, brochures, and promotional items are very much in danger of becoming 'extinct'. Cardboard and styrofoam boxes used to store systems and games, as well as instructions, background stories and such printed material, are more difficult to preserve due to space constraints-and may have often been thrown away entirely or in part soon after the item was purchased. Meanwhile, these items have greatly contributed to the entire experience of the product, and remain testament to the way digital culture has been seen in that day and age. Their value is unquestionable.

More than in most preservation projects, time is of the essence when preserving digital heritage items. The original storage media, such as ROM cartridges or magnetic tapes and disks, and even early CD-ROM discs, have a limited lifespan, a problem recognized also in the UNESCO brochure [20]. For example, there are dozens of prototype cartridges that we know to exist but have not been stored in ROM images. Acquiring these items before they disappear is the goal of a number of collectors, and active collaboration is taking place. To name an example, the Pelikonepeijoonit group sent a copy of the extremely rare Sega Master System game Smurfs 2 to Omar Cornut, a French specialist on the preservation of Sega Master System and compatible games, to be transferred from a cartridge to an ordinary file and archived [2].

This period also implies that the definition of 'antique' needs to be updated for the purposes of digital culture. Computers and game systems become obsolete and are replaced and recycled in a much quicker cycle than, say, automobiles or other consumer goods. With their in-built low life expectancy, computer and video games and other software run a risk of becoming partially or completely destroyed within 20 years of their introduction.

In terms of arranging exhibitions and joint efforts to preserve digital culture, cooperation with businesses has already been rather rich, as can be seen in the history of the Pelikonepeijoonit project. Companies have sensed public interest in old hardware and software and their attraction value for presenting new products. Meanwhile, offers and contacts from the public sector have been much scarcer, with the Digital Archaeology exhibition [13] being the only significant materialized product of this cooperation.

\section{Conclusion}

The history of Pelikonepeijoonit connects with the history of Finnish digital heritage preservation, and one is necessarily part of the other. The website started out as a single hobbyist project arising out of the need to experiment and publish content on the internet. It has since gained significant attention and coverage outside the collector circles. All the while, collecting and archiving artifacts related to our digital heritage has gained more and more mainstream appeal.

From a preservation point of view, some important issues stand out from our study. The collectors have been able to build noteworthy collections with modest sums of money: ten thousand Euros-the maximum reported in the results-is a relatively large sum for an individual, but in the scale of a museum or a foundation, it is not. The key to the collectors' success is the devotion of time coupled with knowledge of 
the domain. Similarly, the storage of items is clearly a problem for an individual, but less so for a museum. Finally, the reported rise of collectible prices such as in internet auctions suggests that the preservation efforts will become increasingly expensive over time.

In conclusion, the present time would be favorable for setting up national bodies to represent digital gaming and collectors, and starting a widespread project to preserve the history of home computing and digital gaming in general, and that of Finnish computing and gaming in particular. The prices of items are on the rise, but still seldom beyond the reach of well-coordinated public efforts to collect such items. We may also fairly and confidently state that many collectors are willing to participate in a jointly coordinated project by donating extraneous items from their collections. As an example, the Pelikonepeijoonit group helped Game On exhibition coordinator Barry Higgins by donating several Pong-type machines to be used by visitors in the exhibition.

Copyright legislation needs to take a clearer stand towards digital software products, taking into account their shorter life span when compared to other items. We argue that the publisher of a fifteen-year-old software product is no longer losing money since people are emulating it on modern computers. Meanwhile, the systematic, legal archiving of these items, both offline and online, would greatly benefit the preservation of the artifacts. Already, there is a large gray area known as 'abandonware' on the internet. It consists of software for which nobody is claiming copyright. The current legal point-of-view to archiving is counter-intuitive and may discourage people from sharing information on the products in question.

\section{References}

[1] Bagnall, B.: On the edge: the spectacular rise and fall of Commodore. Variant Press (2005)

[2] Cornut, O.: The Smurfs Travel the World (2000), http: / / www. smspower. org/db/smurfs2 . shtml (Accessed 16/4/2007)

[3] DigiCULT: The DigiCULT Report. Technological Landscapes for Tomorrow's Cultural Economy. Unlocking the Value of Cultural Heritage. European Commission, Directorategeneral Information Society (2002)

[4] Forster, W.: The Encyclopedia of Game. Machines-consoles, handhelds \& home computers, 1972-2005. Gameplan (2005)

[5] Edge: Edge presents Retro. Future Publishing (2002)

[6] Edge: Edge presents FILE, vol. 1, 2, 3. Future Publishing $(2006,2007)$

[7] Haddon, L.: Elektronisten pelien oppivuodet (The early years of the electronic games). In: Huhtamo, E., Kangas, S. (eds.) Mariosofia, pp. 47-69. Oy Yliopistokustannus University Press, Finland (2002)

[8] IPstat: Statististics for counter: The Arctic Computer \& Console Museum (2007), http : / /www.ipstat. com/cgi-bin/stats ? name=pkpipstat (Accessed 15/4/2007)

[9] Kent, S.L.: The ultimate history of video games: from Pong to Pokemon-the story behind the craze that touched our lives and changed the worldq. Prima Publishing (2001)

[10] Pelikonepeijoonit: Pelikonepeijoonit site updates in 1999 (1999), http: / /www.pelikonepeijoonit.net/olds1999.txt (Accessed 15/4/2007) 
[11] Pelikonepeijoonit: Pelikonepeijoonit site updates in 2000 (2000),

http: / /www.pelikonepeijoonit.net/olds2 000 .txt (Accessed 15/4/2007)

[12] Pelikonepeijoonit: Gameworld 2002. Finland's biggest gaming event (2002),

http: / / www . pelikonepeijoonit. net/articles/gw2k2 . html

(Accessed 15/4/2007)

[13] Pelikonepeijoonit: Digital Archaeology, Exhibition at Tyrvää Museum, Vammala, Finland (2003),

http://www.pelikonepeijoonit.net/articles/vlamuseum.html

(Accessed 10/4/2007)

[14] Saarikoski, P.: Pioneerien leluista kulutuselektroniikaksi. Suomalainen kotimikroharrastus tietotekniikan murroksessa 1980-luvun alusta 1990-luvun puoliväliin (From pioneer toys to consumer electronics. The Finnish computer hobbyists during the computer revolution from early1980s to the mid-1990s). Turun yliopisto (University of Turku) (2001)

[15] Saarikoski, P.: Koneen lumo. Mikrotietokoneharrastus Suomessa 1970-luvulta 1990luvun puoliväliin (The Lure of the Machine. The Personal Computer Interest in Finland from the 1970s to the mid-1990s). Nykykulttuurin tutkimuskeskuksen julkaisuja 83. Jyväskylä (2004)

[16] Scholz, A.: I am 8-bit. Sceen, Issue 01, pp. 60-65. CSW Verlag (2005)

[17] Science Museum: Game On (2006), http://www.sciencemuseum.org.uk/visitmuseum/galleries/ game_on.aspx (Accessed 16/4/2007)

[18] Suominen, J.: Jassot, jukeboksit ja videopelit intohimon kohteena-peliautomaattien keräily Internetissä (Pajazzos, jukeboxes and video games as a passion-game machine colledtions on the Internet). Agricolan tietosanomat, 2/1999 (1999),

http: //agricola.utu.fi/tietosanomat/ numero2-99/pelihistoriat.html (Accessed 28/11/2008)

[19] Suominen, J.: Koneen kokemus. Tietoteknistyvä kulttuuri modernisoituvassa Suomessa 1920-luvulta 1970-luvulle (Experiences with machines. Computerised culture in the process of Finnish Modernisation from the 1920s to the 1970s). Osuuskunta Vastapaino (2003)

[20] UNESCO: Charter on the Preservation of the Digital Heritage (2003)

[21] Yli-Parkas, H.: Keräilijöille kelpaa kaikki Tex Willereistä Pokémoneihin (The collectors are interested in everything from Tex Willer to Pokémon). Keskipohjanmaa 17/4/2000 (2000) 